\title{
Conservation strategies for the Green Island Human Rights Memorial Park
}

\author{
H. M. Hsu \\ Department of Architecture, Chaoyang University of Technology, Taiwan
}

\begin{abstract}
The Green Island, situated in the south-eastern seas of the mainland of Taiwan, although it is blessed with an abundance of fishery resources thanks to the dynamic Kuroshio regime passing through the nearby seas, remains an insulated island unexplored by the outside world. For its unique natural environment, in 1911, during the Japanese occupation era, it was chosen for building prisons for detaining criminals. Following the Second World War, with the Chiang Kai Shek's regime retreating to Taiwan, it was once again chosen for building concentration prisons, largely for detaining political dissidents or rebels. It was not until the deregulation of the Marshal Law in 1978 that the Green Island's prison humanity history witnessed yet another unique humanity heritage in Taiwan's development history. With Green Island prison facilities becoming dilapidated, where the buildings are at risk of toppling, coupled with a majority of the victims held in the earlier concentration camps growing old, the Council for Cultural Affairs has commissioned a study team to conduct an investigative study on the historic buildings. To explore the landscape of the human rights memorial park and its preservation value, the thesis aims to broach from the perspective of cultural landscape how it encompasses an interactive correlation between humans and the natural environment. With that, this paper emphasizes at discussing how the tangle space evolves along the natural environment, social background, economic criteria, and so forth in anticipation to present a set of conservation strategies for integrating the region's humanity history and environment.

Keywords: the Green Island Human Rights Memorial Park, Taiwan, the concentration camp, conservation strategies, cultural landscape.
\end{abstract}




\section{Introduction}

After the Second World War the Kuomintang Government imposed a prolonged curfew in Taiwan, following which the society of Taiwan experienced a long period of suppressive rule. The international community paid much attention to the issue of human rights in Taiwan. The Memorial Park of the Green Island Incident for Human Rights is to be established in remembrance of the internees of the prisons of this period, through whom the democratic development in Taiwan could be charted. From January to October 2006, the present working group was entrusted by the Council for Cultural Affairs to investigate and study this Park, and this report has been prepared in order to suggest strategies for preserving the historic buildings and cultural landscape of the Park [1].

In fact, more than 2,000 political prisoners and captives have been imprisoned at the site of the Freshmen Disciplinary Camp in the past, which used to be a brain-washing concentration camp, a product of the international circumstances of the Cold War and the hostility between China and Taiwan, as well as the oppressive political ambiance of that time. The aims of this study are as follows:

(1) To explore the unique historical background of Green Island and the origin and development of the Memorial Park.

(2) To evaluate "the value of the status quo" of the historic buildings and cultural landscape.

(3) To study and suggest preservation strategies for the Memorial Park.

\section{Issues of preservation}

The essence of preservation of historical heritage is the conservation of the authenticity. The facilities of the original prison in the Memorial Park underwent several stages of change, and due to this process of transformation the buildings contain many different architectural styles. Henri Lefebvre proposed that space and landscape is a social relation; in other words, space is a product of society that will not merely be submissive to the natural environment, and it is also constructed through a distinctive social relation and process $[2,3]$. Therefore, the main concern of this research is to examine methods of preserving those different architectural styles while demonstrating the features of different periods.

The preservation of the spatial resources of cultural heritage sites should begin with examination of values in conservation. While intervention in the current situation of historic buildings and public spheres seems necessary, the cultural heritage expert B. M. Feilden [4]notes that there are 7 different degrees of intervention: (1) prevention of deterioration; (2) preservation of the existing state; (3) consolidation of the fabric; (4) restoration; (5) rehabilitation; (6) reproduction; and (7) reconstruction.

While maintaining the principles of authenticity and non-violation of the holistic harmonious design, necessary interventions for preservation are accepted. However, such interventions will only be implemented after sufficient consideration and feasibility evaluation, so as to avoid possible damage resulting 
from abusive or improper use, as well as idleness. While memorial, educational and recreational functions will be emphasized in the development of the Park, we must be careful to ensure that the hasty pace of development does not unintentionally destroy the elements that would convey a solemn ambiance, such as the structural design, relics and landscape of the concentration camp. An extensive public program will give the Memorial Park the glow of new splendor, but at the same time its authenticity may be lost. Therefore, the preservation strategies will stress ways of preserving the space and ambiance of the past while implementing the necessary renovation works and building additional buildings. In this study, we aim to shed new light on the holistic preservation of the Park's historical meanings and architecture in its unique physical and social contexts.

\section{Origins and development of the Green Island Human Rights Memorial Park}

Green Island is not only unforgettable in the course of human rights development, but also represents an important yet sad historical lesson. The Freshmen Disciplinary Camp (1951-1965) and "Oasis Villa" (1972-1987) in the Park were two major places of imprisonment of internees during the two periods of White Terror in Taiwan. Moreover, they were among the most important landmarks in the evolution of international human rights.

\subsection{Historical development and changes on Green Island}

Green Island was an important site of migration and settlement of indigenous Taiwanese, but literature concerning its history is rather limited, and by the time the island appeared in historical records, it had already been settled by the Han Chinese. Thus, in order to extend the magnitude of the understanding of temporal and spatial spans of the history of the island, further archeological studies concerning human activity on the island before the settling of the Han Chinese should be carried out. According to the oral history of the Han Chinese in the locality, there were conflicts between the Han people and the natives of Green Island. This discovery illustrates that before the migration of the Han Chinese a settlement of native people already existed on the island. The migration history of the natives and Han Chinese are important elements in reconstructing the history of human activity on the island [5].

Since 1990, the development of agriculture, fishery and husbandry on the island declined rapidly or was nearly stagnant, while there was a rapid growth of domestic tourism within Taiwan. Therefore, numerous development plans have been introduced all over the island, for example, the construction of the island ring road, wild camp sites, landfills, extended airport runways, a tourist information centre, trail walks, hot spring facilities, hotels, yacht ports and scuba-diving sites. In addition, power and water supplies, and telecommunication networks, were also improved in order to provide favourable and necessary pre-conditions for tourist development on Green Island [6]. 


\subsection{Origins and development of the Memorial Park}

Green Island, which is surrounded by sea with the strong Kuroshio passing through it, resulting in isolation, has long been regarded as an ideal spot for the imprisonment of criminals because of its unique geographical location. The Human Rights Memorial Park, which is about 32 hectares in size, is situated on the coastal flatland in the northeast corner of the island. The earliest imprisonments began in 1911 when the Japanese government decided to build prison facilities on the island in order to isolate criminals. The Prison of the Department of National Defense was deserted for years, after the Green Island Training Institute moved to the main island of Taiwan in June 2002, and the only prison left is the Prison of Green Island in Zhongliao. As there were three prisons on an island no larger than 16 square kilometers, this was arguably of the highest prison-to-land ratio in Taiwan. The high concentration of criminals who committed serious crimes also made the island notorious yet mysterious. The histories of those century-old prisons are not only important assets in the development of Green Island tourism, but also a valuable heritage of the democratization of Taiwan.

The Freshmen Disciplinary Camp (1951-1965) was situated to the west of the Liu-Ma stream on the island. Most of the houses, commonly known as the Shoddy Temporary Chamber, were made of coral reef stone, wood and straw and were built by prisoners. In August 1987 the curfew was ended, and since then human rights have been progressively protected and emphasized, and citizens are no longer governed by martial laws. The Monument to Human Rights was erected in 1999, following which the Human Rights Park was planned and opened to the public in 2002. In the Park there are heartbreaking photographic exhibitions showing prisoners in The Freshmen Disciplinary Camp, oral histories talking about the white terror, and photographs and videos illustrating the suffering of the internees.

\section{Physical context and development of the architectural ensemble}

In this chapter we carefully examine the existing buildings in the Park and analyze the architectural stylistic pedigree and contextual features. All these findings are valuable references for the future preservation priority assessment of the architectural ensemble.

\subsection{Physical context}

Green Island is situated at the meeting point of the West Pacific Ocean and the Continent of Asia; it is also located in the path of the movement of typhoons in Southeast Asia, and its typical climate is hot, humid and stormy, fig. 1. Due to years of volcanic activity, Green Island has become a concave volcano with the shape of an irregular rectangle. Its main landscapes can be divided as follows: coastal coral island, coastal plain, red earth sea terrace and tableland in valleys. 


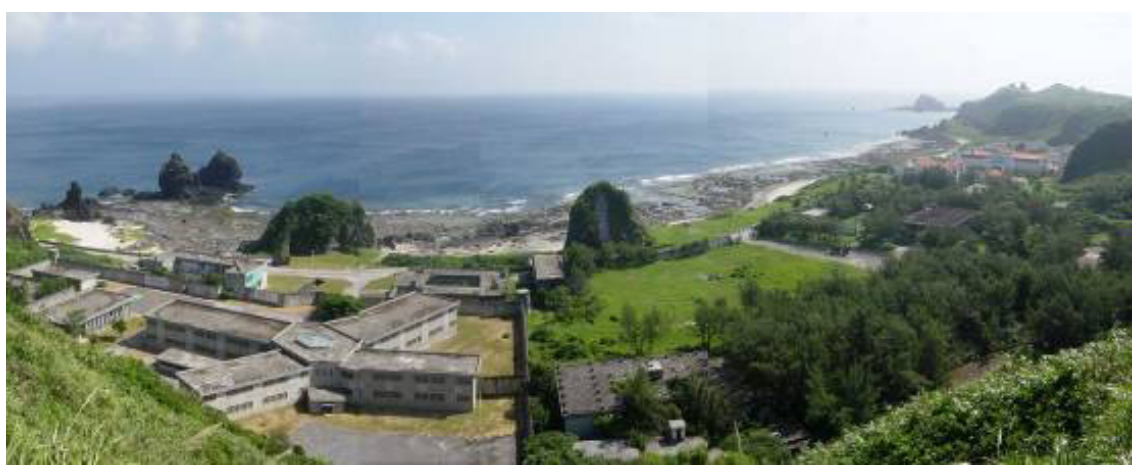

Figure 1: A bird's-eye view of Green Island Human Rights Memorial Park.

\subsection{The origin and development of the architectural ensemble}

\subsubsection{The arrangement of the buildings in the period of The Freshmen Disciplinary Camp (1951-1965)}

The prison building of the Freshmen Disciplinary Camp is arranged in the form of a concentration camp, with two entrance gates, named "the home for the New Life" and "the gate of revolution". For convenience of management, the internees were assigned to three different regiments. They were then further divided into twelve detachments so as to be under closer supervision, which then formed the architectural ensembles, each composed of four detachments. The three architectural ensembles (twelve detachments) were assembled around a courtyard with an atrium, fig. 2, 3 .

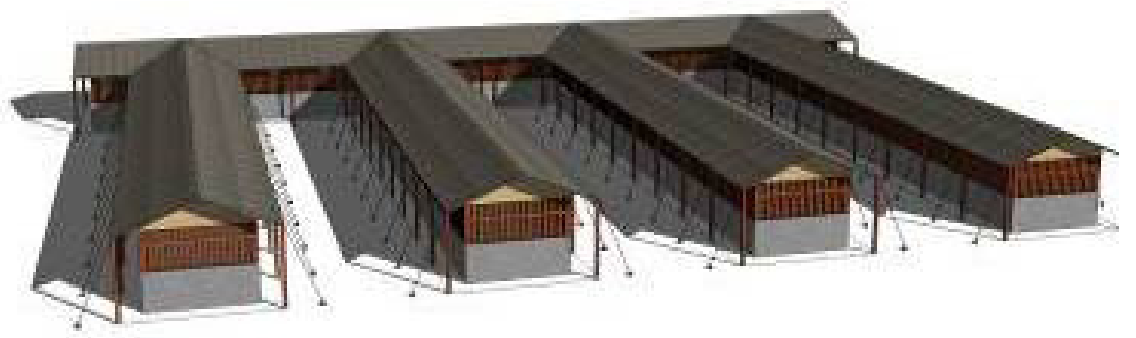

Figure 2: The architectural ensemble in the period of the Freshmen Disciplinary Camp, which comprises four detachments.

\subsubsection{The arrangement of the buildings in the Garrison Command period (1972-1987)}

In 1972, the Garrison Command took over the management. In this period the architectural ensemble of Oasis Villa was planned and built, and blocks of a typical prison form began to emerge. The most striking example of a prison block is the Eight-diagram building, fig. 4 . 


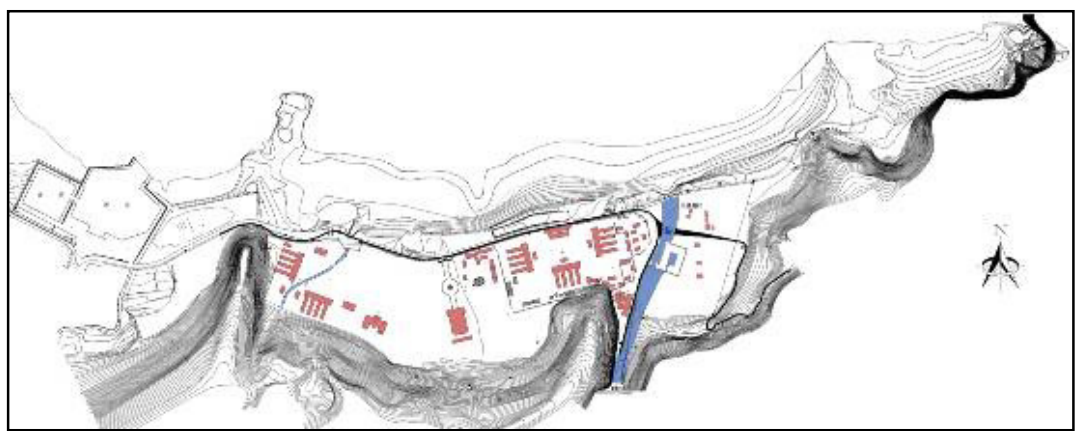

Figure 3: $\quad$ The arrangement of the buildings between 1951 and 1965.

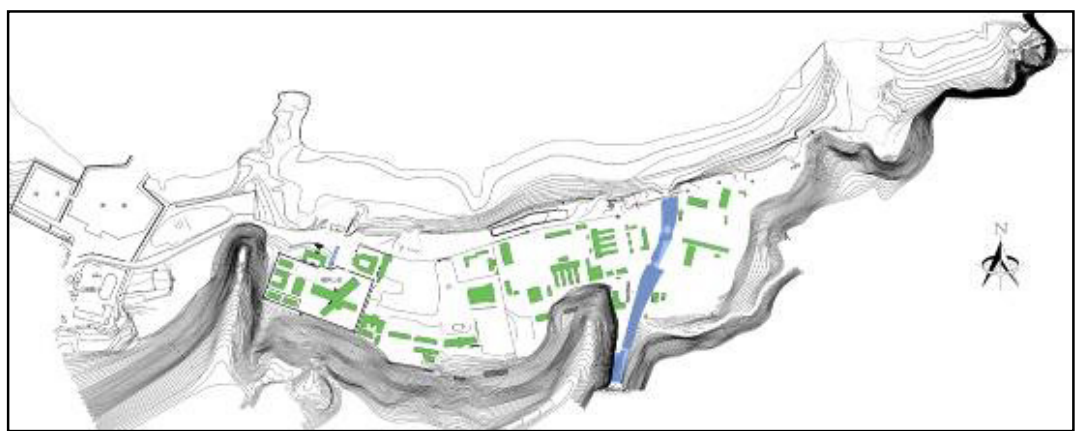

Figure 4: $\quad$ The arrangement of the buildings between 1972 and 1987.

\section{Research on the architectural ensembles and preservation strategies}

The historical essence and the social changes of the island can be manifested through imaginary processes: in other words, people can revisit the past of the internee imprisonments in the concentration camps through the assistance of the existing prison facilities and the extended open space.

\subsection{Criteria for architectural preservation priority assessment}

A series of participatory meetings were held after the completion of the initial situational analysis. The scope of the preservation area and the preservation priorities of the historical architectural ensemble and the open space in the Park were included in the agenda for discussion. The following critical criteria for the assessment of the Green Island Human Rights Memorial Park architectural ensemble are suggested: (a) the period when the building was erected; (b) the exterior structure and interior design; (c) the preservation of originality/primitiveness; (d) reusability in redevelopment. 


\subsection{Preservation strategies for the architectural ensemble}

\subsubsection{Buildings with a high preservation priority}

The use of original materials is encouraged so as to demonstrate the aesthetic sense in the architecture as well as the historical significance of a building [7]. In addition, buildings with a high preservation priority can be restored according to their structural safety with reference to the following guidelines:

5.2.1.1 Buildings with a high level of structural safety The preservation of original designs will be the greatest preservation and restoration principle, including the style and the use of materials, in order to maintain a patina ambiance.

5.2.1.2 Buildings with a medium level of structural safety The original materials should be preserved; however, necessary restoration should follow the original construction methods, materials, and tone and color. On special occasions, when the benefit is justified, modern technology and materials can be partially applied.

5.2.1.3 Buildings with a low level of structural safety On the condition that there is sufficient protection and precautions taken, the remains of buildings can be preserved with the help of the establishment of commemorative plaques or monuments. Only when there is no appropriate plan for preservation or restoration can reconstruction imitating the old form be considered.

\subsubsection{Buildings with a medium preservation priority}

For those buildings with a medium preservation priority, restoration and preservation works should avoid any potential loss of structural features and the historical implications attached. The following guidelines are references for the restoration work of buildings with medium preservation priority according to different levels of structural safety:

5.2.2.1 Buildings with a high level of structural safety Daily maintenance should be emphasized, and localized repair can be carried out.

5.2.2.2 Buildings with a medium level of structural safety In accordance with the principle of completeness, localized alterations (destruction and/or construction) of the original structure are justified; however, the alterations cannot be so prominent as to overshadow the original works. A perfect balance of new and old structures, as well as a harmonious setting, must be maintained by the use of subtle methods and identifiable new materials for measurement and detailing.

5.2.2.3 Buildings with a low structural safety On the condition that there is sufficient protection and precautions taken, the remains of buildings should be preserved or restored according to the aforementioned principles. 


\subsubsection{Buildings with a low preservation priority}

The functions of buildings with a low preservation priority can be revisited in the light of future development blueprints; however, redevelopment plans should take the entire design of the Park into consideration. The following guidelines are references for the restoration work of buildings with a low preservation priority according to different levels of structural safety:

5.2.3.1 Buildings with a high level of structural safety Daily maintenance should be emphasized, and localized repair can be carried out.

5.2.3.2 Buildings with a medium level of structural safety Large scale restoration can be carried out. Given that the structures are intact, one can implement methods that not only can prevent possible destruction but also bring minimum changes. Therefore, the existing structures or historic space can be preserved in a perfect balance in terms of their styles and materials.

\section{Investigation into open space and landscape preservation strategies}

\subsection{Spatial distribution during the period of the Freshmen Disciplinary Camp}

About a hundred coral reef stone buildings were built during the period of The Freshmen Disciplinary Camp, mainly for storage purposes. The daily life of prisoners was not only confined to hard labor but also participation in brainwashing courses, from which their progress of ideological change could be monitored. In addition, in order to establish good relationships with locals and serve as an outlet for the prisoners' excessive energy, regular cultural and recreational functions were held by the local authority. Furthermore, the medical centre of The Freshmen Disciplinary Camp was also open to public for medical consultation and clinical treatment.

The daily activity tracks for prisoners were mainly located in the areas around the Third Squadron and its adjacent water supply spot near the Liu-Man Stream. The distance between the farthest kitchen and the water supply spot in the LiuMan Stream was $400 \mathrm{~m}$ for a single trip ( $800 \mathrm{~m}$ for the return trip), and the usual journey to collect water would be to depart from the side entrance of the Twelfth Detachment of The Freshmen Disciplinary Camp, pass through the playground in the quarter, then finally reach the Liu-Man Stream.

\subsection{Analysis of open space in the Park}

This analysis applies the technique of overlapping layers of maps to compare the existing open space and the important cultural landscape during the different periods. From this analysis we can conclude that there are two distinctive sections in the Park, namely, man-made landscape and natural landscape. 
(1) The oppressive atmosphere created by the architectural ensembles permeates through buildings erected in different periods and space constructed by wallenclosed buildings, and can actually reflect its nature in human rights issues as well as marks of daily life. The connectedness among buildings, humans and land hinges upon the power relation between the ruler and the ruled.

(2) The best sightseeing spots for viewing the natural environment in the Park are the open-air wall of the landscape area of the Park and the costal seafront in the north. The sounds of the waves at the shores soften the daunting feeling of the internal areas of the Park. Therefore, a unique feature of the Park results when a sharp contrast is formed between the visual environment constructed by both the 'visual openness' at the shorelines and the 'oppressive confinement' inside the Park.

\subsection{Preservation strategies for cultural landscape}

The main element of cultural landscape preservation should be the display and demonstration of various confining atmospheres at the same time. Preservation priority should be considered according to the age of the buildings, and the remains of the spatial distribution from the earliest period should be given the priority to be preserved in their original form. On one hand, the landscape and environment surrounding buildings should be restored; on the other hand, landscapes have distinctive meanings and can be re-used only after consideration of their structural safety and exterior structures, followed by renovation and maintenance, and contextual reconstruction of historical events.

According to the principles of preservation of the structural scale of the building and environmental contexts, we understand the importance of the incorporation of sustainability into the design, which is in line with the concern of re-usability in the future. Therefore, we wish to enhance the cultural values of the Park by stressing the contextual experiences. The following five elements can be considered during the preservation of cultural landscape: oppressive environment, environment for imagery, implicit meanings in the surrounding environment, contextual locations and symbols of curfew law.

\section{Conclusion}

Echoing the notion of 'think globally and act locally,' the preservation project of the Green Island Human Rights Park will actually be a testimony of the historical development of international human rights in 20th Century. First of all, the preservation strategies focus on the research on the cultural form of the space. The research premise is that the form of building in itself is a product of a particular society and series of historic contextual progresses. Therefore, spatial arrangement and man-made environmental changes always contrast sharply with the surrounding natural environment, one example being the very construction of an exceedingly brutal concentration camp on a picturesque island like Green Island. 
Furthermore, the following conclusion is drawn after the completion of the fieldwork research and surveying work. The disserted architectural ensembles in the Park and the damaged remains of structural parts on their own are plain and unattractive: however, when they are placed within the entire architecture and open space, the oppressive, confining atmosphere infused in the natural and physical contexts makes them distinctive spatial symbols commemorating the period when Taiwan was under curfew.

The Operational Guidelines for the Implementation of the World Heritage Convention [8] emphasizes that the key meaning of cultural landscape should be its special nature of being a 'combined work of nature and of man.' There are, of course, numerous buildings in the Green Island Human Rights Memorial Park that deserve to be registered as historic buildings; however, this research further proposes that the Park's peculiar nature as an organically evolved landscape, under Category II of cultural landscape, should not be ignored.

\section{References}

[1] Hsu, H. M. \& Chen, B. N., Investigation of Historic Buildings in Green Island Human Rights Memorial Park and the Restoration Proposal, Entrusted by The Council for Cultural Affairs, 2006.

[2] Lefebvre, H., Space Social Product and Value, Critical Sociology European Perspective, New York: Irvington, pp.285-295, 1979.

[3] Huang, I. K., Space, Power and Society, Academia Sinica, Institute of Ethnology, 1995.

[4] Feilden, B. M., Conservation of Historic Buildings, Architectural press, third edition 1994, first published 1982.

[5] Chao, A. X., Green Island Record, Green Island Township Office, 1998.

[6] The Hinsheng Construction Consultant firm, the Proposal of Development of General Tourism in the Specified region in the Eastern Coastal Area of the Green Island entrusted, by the Eastern Office of the Transport Department, pp. 12-15, 1993.

[7] Damish, H., Viollet-le-Duc l'Architecture raisonnée, Hermann édition des science et des arts, ISBN 2-7056-5888-5, pp.39-57, 1990.

[8] World Heritage Centre, whc.unesco.org/en/guidelines 